\title{
Technology III: in-line vaporizer with reflector
}

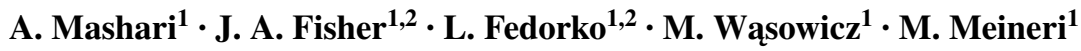

Received: 23 June 2017 / Accepted: 28 October 2017 / Published online: 9 November 2017

(C) Springer Science+Business Media B.V., part of Springer Nature 2017

\begin{abstract}
As the clinical advantages of vapor anesthesia (VA) for sedation of patients in ICU become more apparent, the ergonomics, economy and safety issues need to be better addressed. Here we describe the use of a new commercial digital in-line anesthetic vaporizer that can be attached to the inspiratory limb of a ventilator. If used with a simple, and easily assembled secondary circuit and anesthetic reflector, the circuit remains remote from the patient, the VA consumption approaches a physical minimum, VA level is controlled and monitored, and the tidal volume size is not limited.
\end{abstract}

Keywords ICU sedation · Vapor anesthetic · Reflector · In-line vaporizer

\section{Introduction}

To sedate a patient in the ICU with inhalational vapor anesthetic (VA), one can (a) introduce an anesthetic machine into the patient room; (b) interpose an anesthesia conservation device between the ventilator and the patient. Here we introduce a third option: the insertion of a secondary circuit containing an anesthetic reflector and an in-line vaporizer that accurately delivers a set inspiratory anesthetic concentration in the inspiratory limb of the circuit.

J. A. Fisher

Joe.fisher@utoronto.ca

1 Department of Anesthesia and Pain Management, Toronto General Hospital, University Health Network, University of Toronto, Toronto, Canada

2 Thornhill Research Inc., Toronto, Canada
What are the considerations? With standard anesthetic machines and circle breathing circuits, exhaled gas containing anesthetic is partially recycled to the extent that the fresh gas flow is less than the minute ventilation. As the anesthetic loss is roughly equal to the fresh gas flow $\times$ the exhaled anesthetic concentration its maximum efficiency is at the lowest fresh gas flows [1]. But anesthetic machines are cumbersome in an ICU where space is at a premium, and such machines are unfamiliar to ICU staff, nor are they certified for such out-of-the OR use without the constant presence of an anesthesiologist. In addition, anesthetic machines generally do not offer the full range of ventilation functionality that is available on most modern ICU ventilators.

Adding vaporizers to ICU ventilators would be highly inefficient as the net fresh gas flow is equal to minute ventilation; adequate scavenging would be difficult, and in any event, would contribute unnecessarily to atmospheric pollution (see Yasny and White [2] for review).

Anesthesia conservation devices (AnaConDa ${ }^{\mathrm{TM}}$, Sedana Medical AB, Uppsala, Sweden; Mirus ${ }^{\mathrm{TM}}$, Pall Medical, Dreieich, Germany [3]) can be interposed between the ventilator and the endotracheal tube. Such devices use a syringe pump to introduce a steady flow of anesthetic into the circuit, and an anesthetic reflector to trap and re-cycle up to 90\% of exhaled anesthetic [4-7]. However, the flow of liquid anesthetic into the circuit must be set manually using trial and error or empirical algorithms [8], and have been associated with a number of complications (see [9] for review). In addition, as the circuit is interposed between the ventilator and the patient, it increases dead space; this, combined with $\mathrm{CO}_{2}$ retention by the reflector, hinders elimination of $\mathrm{CO}_{2}$ [10] and places lower limits on the tidal volume and employment of lung protection strategies. Lastly, the devices are bulky, encumbering access to the head by care givers, and 
Fig. 1 RIVAL circuit. See text for description

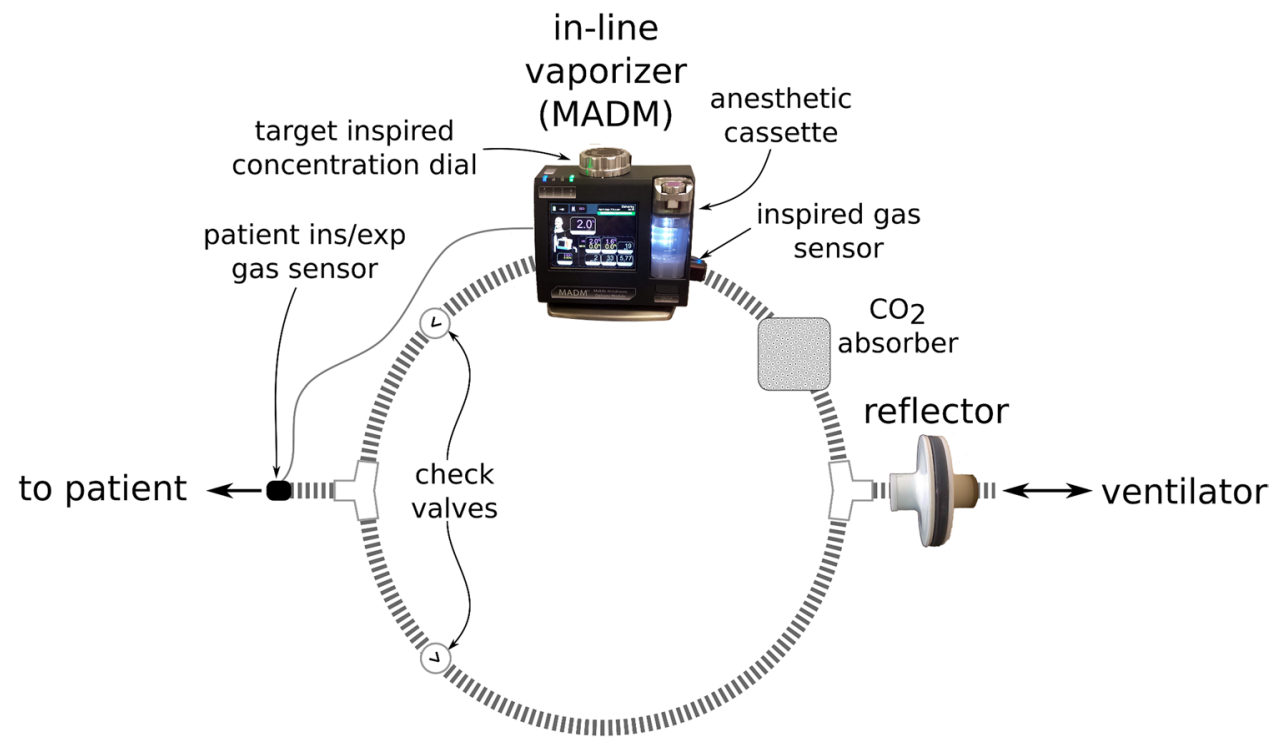

require structural support to prevent traction on the endotracheal tube.

An in-line vaporizer can be placed on the inspiratory limb of both a circle breathing circuit and an ICU circuit. It enables abrupt changes of inspired concentrations of VA independent of inspired gas flow or minute ventilation. Its efficiency is a function of the fresh gas flow, which may be high with a circle circuit at low fresh gas flow; but, if used on the inspiratory limb of an ICU ventilator, its efficiency is low as it remains a function of the fresh gas flow, which, with an ICU ventilator, is equal to minute ventilation.

Here we describe a simple method to combine the most advantageous characteristics of the anesthesia conservation via a reflector and the in-line vaporizer to provide precise anesthetic concentrations and thus the ability to finely tune the degree of sedation to the clinical requirements. The goal is to provide precise, highly efficient, automatic, control of inhaled concentrations of anesthetic, independent of fresh gas flow, with low dead space, and unencumbered nursing access to the patient.

This is accomplished by placing a commercially available in-line vaporizer $\left(\mathrm{MADM}^{\mathrm{TM}}\right.$, Thornhill Medical Inc. Toronto, Canada) (Fig. 1) in the inspired limb of an improvised secondary circuit that contains an anesthetic reflector and readily available components (two one-way valves, a small $\mathrm{CO}_{2}$ absorber, $22 \mathrm{~mm}$ corrugated tubing, and connectors; Reflector-In-line-Vaporizer Anesthesia AppLication, or RIVAL circuit-Fig. 1). The ventilator connects to the reflector, and a Y-connector on the patient side of the reflector connects to the secondary circuit. A one-way valve directs ventilator flow to an inspiratory limb that contains, sequentially, a small $\mathrm{CO}_{2}$ absorber, MADM ${ }^{\mathrm{TM}}$ and corrugated tubing leading to the patient connector. The expiratory limb consists of corrugated tubing and an expiratory one-way valve connecting to the patient side of the reflector, completing the circuit.

As with the AnaConDaTM, the reflector retains the anesthetic vapor from exhaled gas and recycles it for the next inspiration. On inspiration, the $\mathrm{CO}_{2}$ absorber scrubs the small amount of $\mathrm{CO}_{2}$ returned from the dead space and retained by the reflector. The $\mathrm{MADM}^{\mathrm{TM}}$ in-line vaporizer (Fig. 2) senses the anesthetic concentration and gas flow, and adds anesthetic vapor to bring the inspired concentration of anesthetic up to that set on the vapor-setting dial. Increased anesthetic concentrations can be implemented in just two to three breaths (Fig. 3). When reducing anesthetic

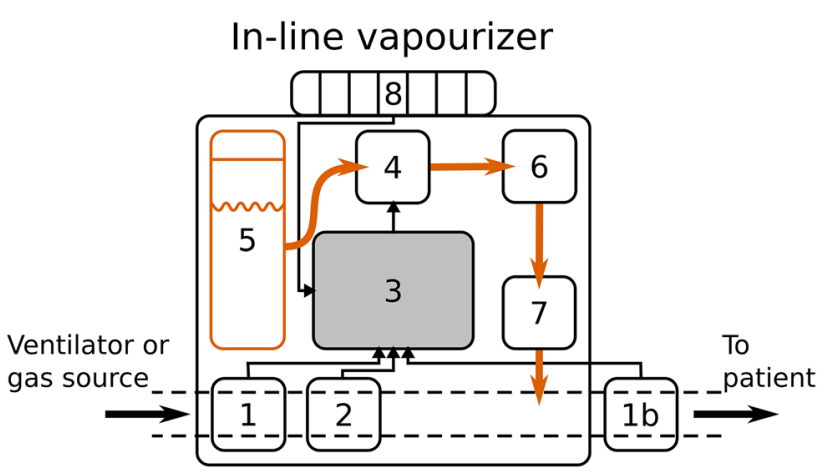

Fig. 2 Schematic diagram of MADM ${ }^{\mathrm{TM}}$ in-line vaporizer. This vaporizer is interposed on the inspiratory limb of any circuit. It senses the input flow [1] and volatile anaesthetic (VA) concentration [2]. The data processor and device controller [3] compares the input mass of VA with the target output designated by the dial [8]. It instructs the pump [4] to transfer VA from the anaesthetic reservoir [5] to the vaporization chamber [6] and the vapor pump [7] to top up the inspired gas with the appropriate mass of VA to meet the target concentration. Sensor [1b] is attached to the endotracheal tube and monitors inspired and end-tidal anaesthetic concentrations 


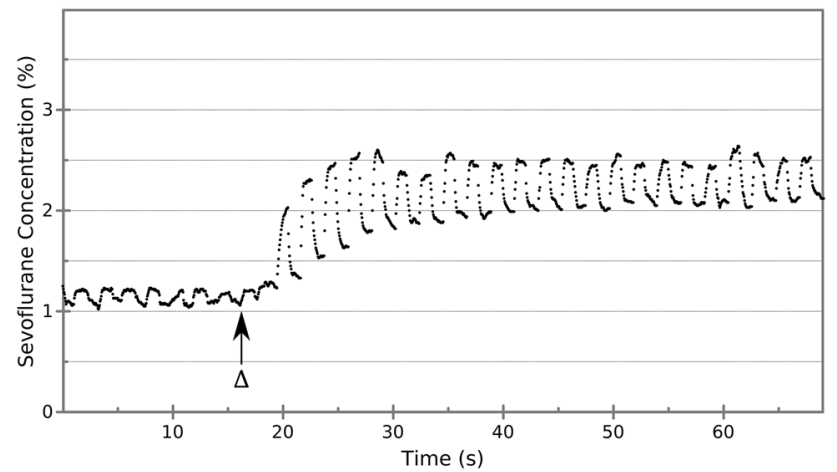

Fig. 3 Tidal Sevoflurane concentrations with a MADM ${ }^{\mathrm{TM}}$ in-line vaporizer on the inspiratory limb of a circle anesthetic circuit. The circuit is attached directly to an endotracheal tube ventilating an anesthetized $50 \mathrm{~kg}$ pig. There is no intermediary secondary circuit for this demonstration of its capability to change VA concentration. The Sevoflurane concentration selection dial was set from 1 to $2.5 \%$ at the arrow. The figure illustrates that it took five breaths to reach the set inspired Sevoflurane concentration (data from Mashari et al. [11])

concentrations, MADM ${ }^{\mathrm{TM}}$ does not deliver any additional anesthetic until the new target is reached. However, with the reflector in place, reduction in anesthetic concentration is slowed but may be speeded up by removing or bypassing of the reflector (as is recommended with the AnaConDa ${ }^{\mathrm{TM}}$ ).

\section{Discussion}

The availability for the first time of a commercial in-line vaporizer in North America and Europe is the crucial element leading to the high efficiency and versatility of anesthetic delivery. The RIVAL is a universal circuit in the sense that can be used with any ventilator, any ventilator circuit (including a circle anesthetic circuit), a self-inflating bag, and even with spontaneous ventilation (no ventilator, no circuit)-all while retaining very high efficiency of anesthetic delivery (Fig. 4), and without the $\mathrm{CO}_{2}$ retention caused by the reflector alone (due to reflector deadspace and $\mathrm{CO}_{2}$ reflection).

RIVAL is a simple circuit constructed from familiar, inexpensive components, readily available to Respiratory Therapy, Intensive Care Medicine, and Anesthesiology departments in most hospitals. If required, it can be assembled and distributed commercially by local component providers. The $\mathrm{MADM}^{\mathrm{TM}}$ and $\mathrm{CO}_{2}$ absorber can be placed at a convenient distance from the patient (e.g., on the ventilator) with only tubing and Y-connector attached to the endotracheal tube, without adding to the dead space.

The added circuit compliance of the RIVAL should not affect the sophisticated ventilation patterns provided by modern ICU ventilators. In pressure control modes, there is clearly no problem. In volume control mode, all modern

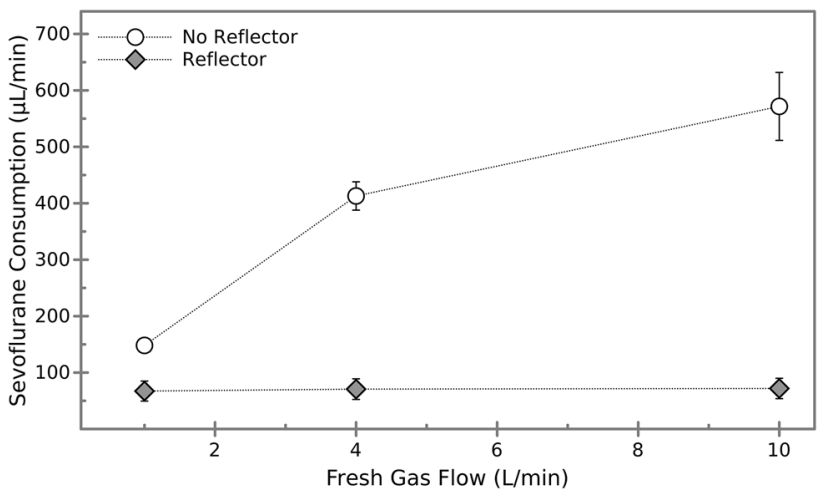

Fig. 4 Sevoflurane consumption as a function of fresh gas flow in a circle anesthetic circuit. The circle anesthetic circuit is attached to a secondary circuit illustrated in Fig. 1. Error bars are standard deviation; study in six $50 \mathrm{~kg}$ pigs (data from Mashari et al. [11])

ventilators have settings and self-performed tests of circuit compliance that allow them to compensate for differences in tubing length and chest compliance from patient to patient. ${ }^{1}$

The system's very high efficiency and low pollution make it ideal for long term use, such as sedation in the ICU. A study in six $(50 \mathrm{~kg})$ pigs in our laboratory (Mashari et al. [11]) showed anesthetic consumption to be reduced to half of that with a circle circuit even at a low fresh gas flow of $1 \mathrm{~L} /$ min (Fig. 4). This level of consumption remained constant and was independent of the fresh gas flow up to $10 \mathrm{~L} / \mathrm{min}$. Sevoflurane consumption was about $60 \mu \mathrm{L} / \mathrm{min}$; this rate of consumption applied to isoflurane would predict costs to be $\sim$ US\$ 0.07-0.15/h in our hospital.

Final comments: Because MADM ${ }^{\mathrm{TM}}$ is in-line it is capable of attaining and maintaining a designated inspired anesthetic concentration within two to three breaths, a feature that makes it highly desirable for inhalational induction of anesthesia, and rapid changes in anesthetic depths to facilitate brief but painful procedures in the ICU. The small size of the vaporizer (about the size of a 2-slice toaster), its tolerance of up to $30^{\circ}$ tilt, and the versatility of the secondary circuit commends it for use outside the ICU as well, such as during transport, imaging or medical procedures outside of the operating room. Indeed, MADM ${ }^{\mathrm{TM}}$ has been ruggedized to be suitable for military field use and would also be suitable for inter-hospital transport and disaster relief.

In summary, the recent commercial availability of an inline vaporizer combined with a secondary ventilation circuit

\footnotetext{
${ }^{1}$ For example, AVEA (Carefusion, Yorba Linda, USA) performs a preparatory self-test to determine total circuit compliance. This would be performed with the RIVAL in the circuit. The iVent (GE Healthcare), performs a brief inspiratory hold to calculate static compliance. However, actual performance of specific ventilators with RIVAL would have to be tested.
} 
enable it to provide well controlled, highly efficient sedation with anesthetic vapor to patients in the ICU.

\section{Compliance with ethical standards}

Conflict of interest JAF is Chief Scientist and shareholder, and LF is a shareholder of Thornhill Research Inc., (TRI) a forprofit spin-off company of the University Health Network and the University of Toronto. The other authors have nothing to declare.

\section{References}

1. Azami $\mathrm{T}$, et al. Calculation of $\mathrm{O} 2$ consumption during low-flow anesthesia from tidal gas concentrations, flowmeter, and minute ventilation. J Clin Monit Comput. 2004;18:325-32.

2. Yasny JS, White J. Environmental implications of anesthetic gases. Anesth Prog. 2012;59:154-8.

3. Bomberg $\mathrm{H}$, et al. A novel device for target controlled administration and reflection of desflurane-the Mirus. Anaesthesia. 2014;69:1241-50.

4. Dahm SL, Steptoe P, Luttropp HH, Reinstrup P. Charcoal as an airway isoflurane reflection filter. Eur J Anaesthesiol. 1998;15:230-3.
5. Tempia A, et al. The anesthetic conserving device compared with conventional circle system used under different flow conditions for inhaled anesthesia. Anesth Analg. 2003;96:1056-61 (table of contents).

6. Thomasson R, Luttropp HH, Werner O. A reflection filter for isoflurane and other anaesthetic vapours. Eur J Anaesthesiol. 1989;6:89-94.

7. Perhag L, Reinstrup P, Thomasson R, Werner O. The Reflector: a new method for saving anaesthetic vapours. $\mathrm{Br} \mathrm{J}$ Anaesth. 2000;85:482-6.

8. Belda JF, et al. The predictive performance of a pharmacokinetic model for manually adjusted infusion of liquid sevofluorane for use with the Anesthetic-Conserving Device (AnaConDa): a clinical study. Anesth Analg. 2008;106:1207-14 (table of contents).

9. Laferriere-Langlois P, d AF, Manzanares W. Halogenated volatile anesthetics in the intensive care unit: current knowledge on an upcoming practice. Minerva Anestesiol. 2017;83:737-48.

10. Sturesson LW, Bodelsson M, Jonson B, Malmkvist G. Anaesthetic conserving device AnaConDa: dead space effect and significance for lung protective ventilation. Br J Anaesth. 2014;113:508-14.

11. Mashari A, Fedorko L, Fisher JA, Klein M, Wąsowicz M, Meineri M. High volatile anaesthetic conservation with a digital in-line vaporizer and a reflector. Actal anaesthesiol Scand. 2017. https:// doi.org/10.1111/aas.13017 